\title{
DESAFIOS DO SANEAMENTO BÁSICO NA HABITAÇÃO POPULAR: UM ESTUDO DE CASO DO RESIDENCIAL JARDIM CERRADO EM GOIÂNIA-GO
}

Otniel Alencar Bandeira ${ }^{1}$, Palmeri de Nazaré Coelho Bandeira ${ }^{2}$, Débora Carolinna Pereira Costa ${ }^{1}$, Patrícia de Faria ${ }^{1}$ e Lúcia Maria Moraes ${ }^{2}$.

${ }^{1}$ Mestrando em Desenvolvimento e Planejamento Territorial pela Pontifícia Universidade Católica de Goiás - PUC Goiás. Goiânia, Brasil. (otnielalencar@gmail.com)

${ }^{2}$ Professora Doutora do Programa de Pós- Graduação em Desenvolvimento e Planejamento Territorial da Pontifícia Universidade Católica de Goiás - PUC Goiás. Goiânia, Brasil.

Recebido em: 08/04/2017 - Aprovado em: 10/06/2017 - Publicado em: 20/06/2017 DOI: 10.18677/EnciBio_2017A147

A rápida e desordenada urbanização das cidades brasileiras gerou profundos problemas urbanos de ordem social, econômica e ambiental. Entre esses diversos problemas destaca-se a expansão das periferias, inexistência ou precariedade dos serviços de saneamento básico. Na segunda metade do século XX o Brasil passou por um período explosivo de crescimento urbano, impulsionado, entre outros fatores, por políticas públicas habitacionais que favoreceram as desigualdades socioespaciais nas cidades e a expansão das periferias. Atualmente o Minha Casa Minha Vida, que é o principal programa da política habitacional brasileira, tem seguido a mesma lógica dos programas do século passado. Um exemplo de conjuntos habitacionais financiado pelo MCMV é o Residencial Jardim Cerrado em Goiânia-GO. O saneamento básico precário constitui um "risco tradicional" à saúde humana e afeta, especialmente, a população de baixa renda. Dessa forma, a presente pesquisa teve por objetivo verificar as condições de saneamento básico do Residencial Jardim Cerrado I a IV - destinado à população de baixa renda - a partir de visitas ao local e percepção dos residentes. A pesquisa foi dividida em três etapas: 1) pesquisa teórica; 2) visitas ao local, elaboração, validação e aplicação do questionário; 3) tabulação e interpretação dos dados. Dos quatro itens avaliados pertencentes ao saneamento básico, o abastecimento de água foi o mais bem avaliado pelos moradores, enquanto o esgotamento sanitário foi o alvo de maiores críticas e descontentamentos. Os resíduos sólidos do bairro merecem ser gerenciados com mais atenção pela prefeitura municipal, porque é exorbitante a quantidade de resíduos descartados em lotes vagos.

PALAVRAS-CHAVE: Cidades. Segregação socioespacial. Programas habitacionais. 


\title{
CHALLENGES OF THE BASIC SANITATION OF POPULAR HOUSING: CASE STUDY RESIDENTIAL JARDIM CERRADO IN GOIÂNIA-GO
}

\begin{abstract}
The rapid and disorderly urbanization of Brazilian cities has generated deep urban problems of social, economic and environmental order. Among these various problems is the expansion of the peripheries, lack or lack of basic sanitation services. In the second half of the twentieth century Brazil experienced an explosive period of urban growth, driven, among other factors, by public housing policies that favored socio-spatial inequalities in cities and the expansion of peripheries. Currently Minha Casa Minha Vida, which is the main program of Brazilian housing policy, has followed the same logic of the programs of the last century. An example of housing complexes financed by MCMV is the Residencial Jardim Cerrado in Goiânia-GO. Poor basic sanitation constitutes a "traditional risk" to human health and particularly affects the low-income population. The present research had the objective of verifying the basic sanitation conditions of the Residencial Jardim Cerrado I, II, III and IV - for the low income population - from site visits and residents' perceptions. The research was divided into three stages: 1) theoretical research; 2) site visits, preparation, validation and application of the questionnaire; 3) tabulation and interpretation of the data. Of the four evaluated items pertaining to basic sanitation, water supply was the most well evaluated by residents, while sewage was the target of greater criticism and discontent. The solid waste of the neighborhood deserves to be managed with more attention by the city hall, because the amount of waste discarded in vacant lots is exorbitant.
\end{abstract}

KEYWORDS: Cities. Socio-spatial segregation. Housing programs.

\section{INTRODUÇÃO}

A urbanização das cidades brasileiras ocorreu de forma desigual, isto é, com grandes diferenças entre classes sociais e regiões. Isso gerou profundos problemas de ordem social, econômica e ambiental como, por exemplo, formação de favelas e periferias, principalmente em grandes centros urbanos, informalidades habitacionais, desigualdades do acesso aos serviços de saneamento básico, entre outros (CARDOSO \& ARAGÃO, 2013). Entre os diversos problemas relacionados ao crescimento acelerado e desordenado das cidades, destaca-se a falta de saneamento básico. A Organização Mundial de Saúde (OMS) declara que o saneamento básico precário se constitui um "risco tradicional" à saúde humana e afeta, especialmente, a população de baixa renda. Entre os riscos associados à inexistência ou precariedade de saneamento, destacam-se diversas doenças como micoses, leptospirose, leishmanioses, filariose, doenças infecciosas intestinais, dengue, entre outras (GALVÃO JÚNIOR et al., 2012).

Na segunda metade do século XX o Brasil passou por um período explosivo de crescimento urbano, impulsionado, entre outros fatores, por políticas públicas habitacionais que favoreceram as desigualdades socioespaciais nas cidades e a expansão das periferias. Além da segregação socioespacial, os programas de habitação popular desse período incentivaram a propagação de grandes conjuntos habitacionais em lugares longínquos onde o assentamento da população pobre era feito em periferias precárias com infraestrutura urbana praticamente inexistente (ROLNIK et al., 2005). 
O principal programa da política habitacional ${ }^{1}$ brasileira atualmente é a Minha Casa Minha Vida (MCMV) que foi lançado em março de 2009 pelo Governo Federal com o objetivo principal de contribuir com a redução do déficit habitacional, através de incentivos à construção e compra de unidades habitacionais, além de minimizar o impacto da crise internacional de 2008 sobre o emprego e o crescimento econômico no país (MÜLLER \& LIMA, 2017). O programa foi estabelecido para atender três faixas de renda distintas, a saber: faixa 1 destinada às famílias com renda mensal de até $R \$ 1.600,00$; faixa 2 para famílias com renda mensal entre $R \$ 1.600,00$ e $R \$ 3.100,00$; e a faixa 3 destinada às famílias com renda entre $R \$ 3.100,00$ e $\mathrm{R} \$ 5.000,00$ (LUCAS, 2016).

Conforme afirma ROLNIK et al. (2005) o MCMV vem desempenhando um papel protagonista "na reprodução da segregação em função da renda e na reafirmação da periferia como lugar dos pobres na cidade (...). O desenho do programa é um fator determinante para a reprodução do padrão periférico da moradia da população de baixa renda no país". Embora alguns municípios assumam a responsabilidade do planejamento da oferta da habitação popular, as regras do programa oferecem autonomia às construtoras para elaboração de projetos e seleção de terrenos. Uma consequência disso é a configuração do programa em um negócio onde a maximização dos lucros é o principal objetivo, e questões importantes como infraestrutura urbana, saneamento básico, qualidade de vida e bem estar dos futuros moradores acabam sendo negligenciadas (MORAIS \& LABAKI, 2017).

Um exemplo de conjuntos habitacionais de interesse social financiado pelo MCMV é o Residencial Jardim Cerrado em Goiânia-GO com mais de 10 mil unidades habitacionais. $O$ residencial localiza-se em região periférica nos limites da mancha urbana de Goiânia e Trindade, esta pertencente à Região Metropolitana de Goiânia (RM). O residencial foi construído em várias etapas, sendo que as quatro primeiras foram destinadas à faixa de renda um do MCMV.

Dessa forma, a presente pesquisa teve por objetivo verificar as condições de saneamento básico do Residencial Jardim Cerrado I a IV - residencial financiado pelo MCMV destinado à população de baixa renda - a partir de visitas ao local e percepção dos residentes. Os aspectos avaliados foram: abastecimento de água, esgotamento sanitário, gestão de resíduos sólidos e drenagem de águas pluviais.

\section{MATERIAL E MÉTODOS}

\section{Caracterização da Área de Estudo}

A pesquisa foi realizada em Goiânia-GO, no período entre março e dezembro de 2016, um estudo de caso sobre o Residencial Jardim Cerrado, localizado na região oeste de Goiânia, à divisa com o município de Trindade. O residencial ocupa uma área de cerca de 500 hectares e fica a $25 \mathrm{~km}$ de distância do centro da cidade. O acesso ao bairro por via asfaltada ocorre pela GO-060 e Avenida Luísa M. Coimbra Bueno. Existe um acesso não asfaltado pela Avenida Vinícius de Moraes que interliga o Jardim do Cerrado ao Conjunto Vera Cruz. $\mathrm{Na}$ área existem importantes áreas de preservação permanente como, por exemplo, a nascente do córrego da Cruz e nascente do afluente do córrego da Cruz, cujo nome é desconhecido (Figura 1).

\footnotetext{
${ }^{1}$ Formulado pelo Sistema Nacional de Habitação de Interesse Social (SNHIS), instituído pela Lei 11.124/2005, e pelo Plano Nacional de Habitação (PlanHab).
} 


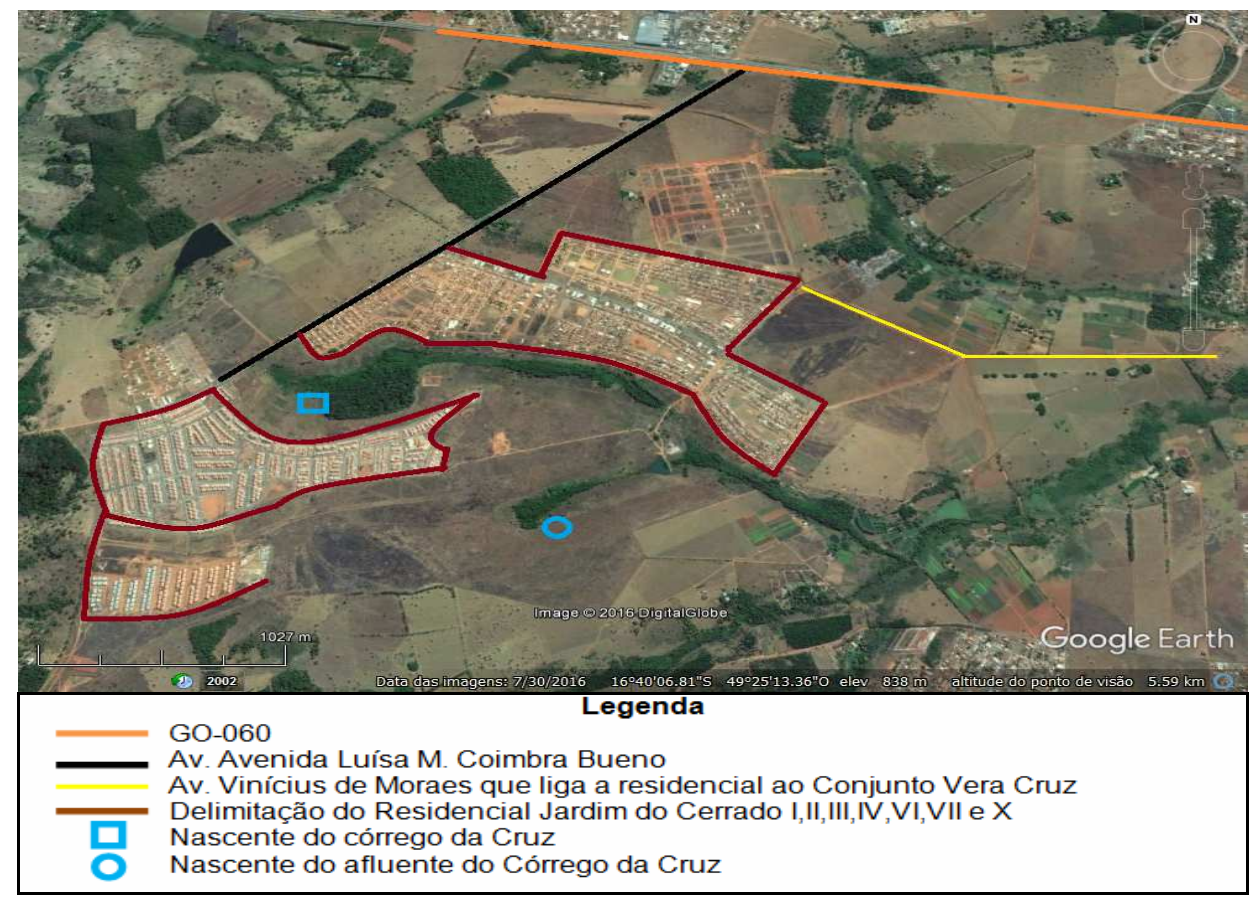

FIGURA 1- Acessibilidade ao Residencial Jardim do Cerrado e áreas de preservação permanente existentes no bairro.

Fonte: Google Earth (2016). Modificado pelos autores.

Embora o Residencial Jardim Cerrado seja constituído por vários módulos, a pesquisa se restringiu apenas aos quatro primeiros módulos por se tratarem de residências destinadas às famílias de baixa renda.

\section{Método}

A pesquisa foi dividida em três etapas: 1) pesquisa teórica; 2) visitas ao local, elaboração, validação e aplicação do questionário a residentes do Residencial Jardim Cerrado; 3) tabulação e interpretação dos dados.

A pesquisa teórica foi realizada em artigos, documentos e livros sobre planejamento urbano, saneamento básico e habitação de interesse popular. $\mathrm{O}$ estudo bibliográfico foi realizado a partir de bases científicas, como Scielo, Scopus e banco de dissertações e teses da Pontifícia Universidade Católica de Goiás (PUC), Universidade Federal de Goiás (UFG) e Universidade Federal do Rio de Janeiro (UFRJ).

$\mathrm{Na}$ segunda etapa foram realizadas visitas ao local para registro fotográfico do bairro e coleta de informações com os residentes para elaboração do questionário. Após a formulação do questionário, o mesmo foi aplicado com alguns moradores para ser testado e validado. Após as correções, o questionário foi aplicado presencialmente a 60 residentes do Residencial Jardim Cerrado I, II, III e IV que continha as seguintes questões relacionadas ao saneamento básico: abastecimento de água, esgotamento sanitário, resíduos sólidos e drenagem de águas pluviais. A terceira etapa correspondeu à tabulação dos dados coletados, organização das informações obtidas por meio das visitas ao local, interpretação e elaboração de redação final deste artigo. 


\section{RESULTADOS E DISCUSSÕES}

O residencial Jardim do Cerrado foi dividido em 11 etapas. Com exceção dos módulos V, VIII, IX e XI, todos os demais já estão consolidados. Os módulos de I a IV que foram destinados aos moradores de áreas de risco e famílias menos favorecidas socialmente foram objetos de estudo deste trabalho. A tipologia das residências nesta faixa é casa isolada no lote (Figura 2).
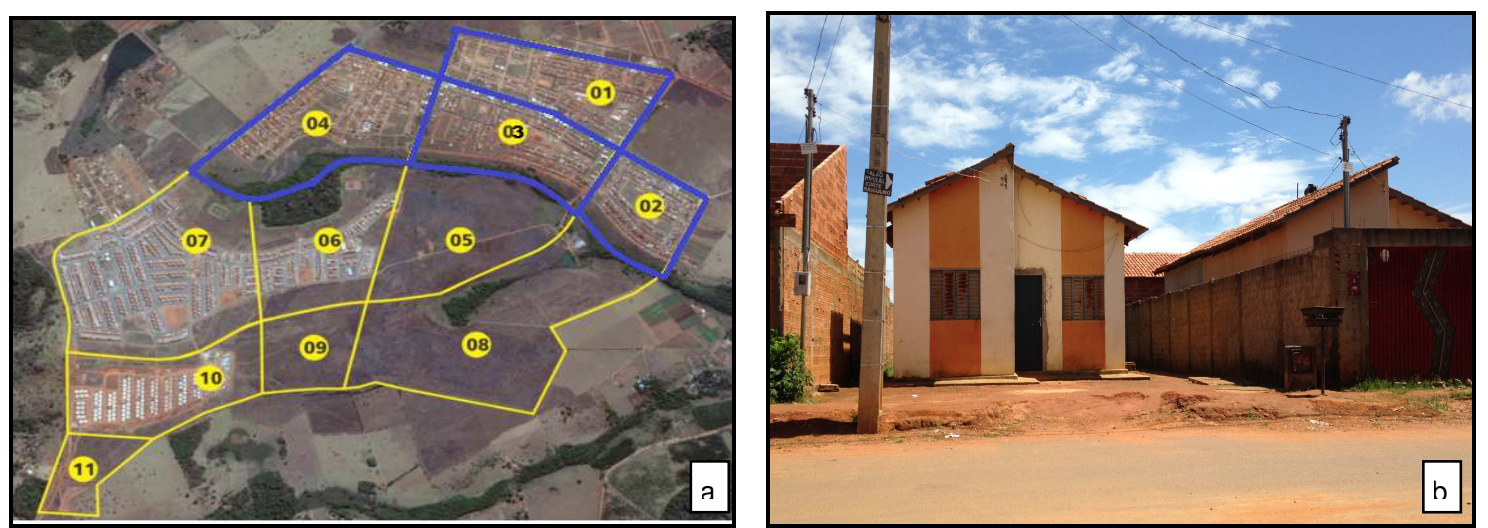

FIGURA 2 - (a) Imagem aérea dos módulos do Residencial Jardim dos Cerrados e (b) tipologia das casas dos primeiros módulos.

Fonte: (a) LUCAS (2016, p.132); (b) Acervo pessoal. Data 20/10/2016

Legenda: - Delimitação dos módulos do residencial —Delimitação da área de estudo

As primeiras perguntas foram realizadas para identificação do nível de conhecimento da população sobre o assunto abordado. A Tabela 1 e a Figura 2 apresentam as respostas dos moradores sobre questões gerais relacionadas ao saneamento básico.

TABELA 1 - Conhecimento dos moradores do Jardim Cerrado sobre saneamento básico, Goiânia-GO.

\begin{tabular}{lcccc}
\hline \multirow{2}{*}{ Questões } & \multicolumn{4}{c}{ Respostas } \\
\cline { 2 - 5 } & Sim & $\%$ & Não & $\%$ \\
\hline Você sabe o que é saneamento básico? & 37 & 61,7 & 23 & 38,3 \\
\hline $\begin{array}{l}\text { Em sua opinião o saneamento básico pode } \\
\text { interferir na saúde da população? }\end{array}$ & 48 & 80 & 12 & 20 \\
\hline
\end{tabular}

Fonte: Elaborado pelos autores (2016)

Apesar de mais da metade dos entrevistados responderem que sabiam o significado de saneamento básico, muitos ainda ficaram confusos no momento em que foi solicitado que marcassem quais serviços faziam parte do saneamento básico (Figura 2). 


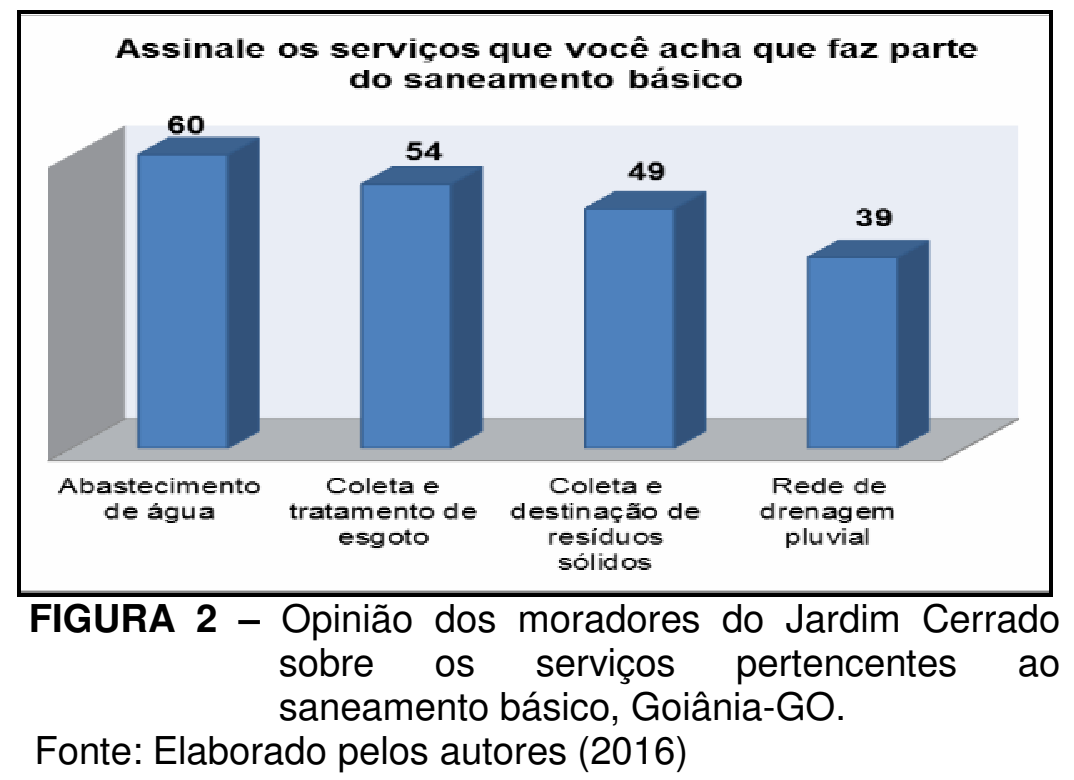

A rede de drenagem pluvial e a coleta e destinação dos resíduos sólidos foram os serviços que mais deixaram os moradores participantes desta entrevista em dúvida. Alguns não sabiam o que significava drenagem pluvial, sendo necessária prévia explicação. Falta muito esclarecimento sobre o assunto e a população ainda se confunde sobre quais os serviços pertencem ao saneamento básico. Após explicar detalhadamente sobre os serviços de saneamento básico, os participantes da pesquisa responderam se estavam satisfeitos ou não com o saneamento do bairro (Figura 3).

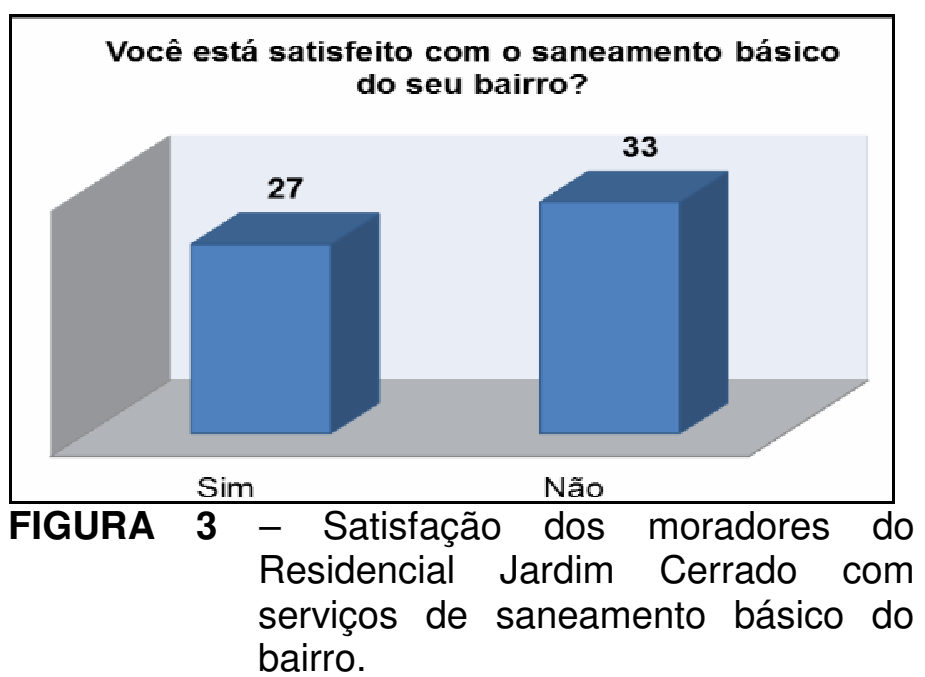

Fonte: Elaborado pelos autores (2016)

Enquanto $55 \%$ dos participantes demonstraram insatisfação com a oferta dos serviços de saneamento básico no bairro, $45 \%$ apresentaram-se satisfeitos. 0 serviço mais elogiado pelos residentes foi o abastecimento de água, enquanto 0 mais criticado foi o esgotamento sanitário.

a) Abastecimento de água

Com relação ao abastecimento de água, os domicílios do Residencial Jardim do Cerrado são $100 \%$ atendidos com rede geral da SANEAGO. A água tratada vem 
do sistema Meia Ponte e precisa passar por diversos bombeamentos até chegar às residências. Até outubro/2016 a SANEAGO tinha conseguido fornecer água em quantidade e qualidade aos moradores do Jardim do Cerrado, sem interrupções no fornecimento e necessidade de expansão da rede, no entanto como a projeção é de crescimento e adensamento populacional, possivelmente nos próximos anos a concessionária necessitará investir na ampliação da rede para conseguir atender a demanda de água (informação verbal) ${ }^{2}$. A Figura 4 apresenta a resposta dos moradores sobre o tipo de abastecimento e qualidade da água.
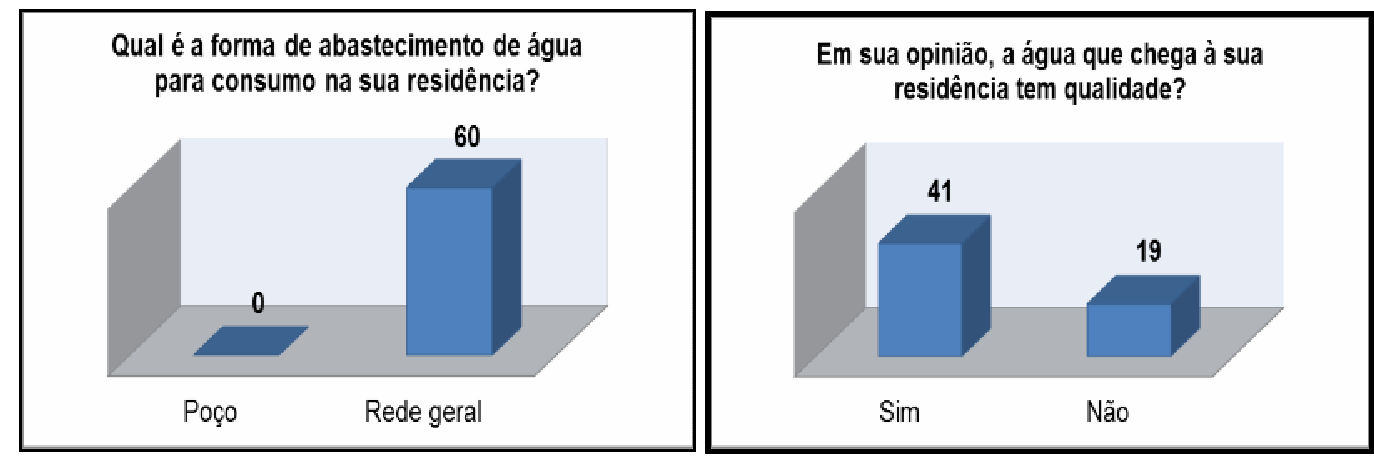

FIGURA 4 - Tipo de abastecimento e qualidade da água segundo informações dos moradores do Jardim Cerrado, Goiânia-GO.

Fonte: Elaborado pelos autores (2016)

Todas as residências dos moradores participantes da pesquisa são abastecidas por rede geral de água. Com relação à qualidade do abastecimento, apenas $32 \%$ dos moradores consideram que a água não possui qualidade. Sobre a frequência da falta de água, $87 \%$ dos residentes responderam que nunca falta água no bairro, $10 \%$ afirmaram que isso ocorre esporadicamente, apenas três vezes ao ano e apenas 3\% apontaram que a interrupção do abastecimento ocorre três vezes por mês.

Segundo MEDEIROS FILHO (2008) um sistema público de abastecimento de água é a solução mais viável em um empreendimento habitacional. Essa solução se torna a mais indicada, por ser mais eficiente na preservação dos mananciais e controle da qualidade da água distribuída à população. Para XAVIER \& LORETO (2016) o fornecimento de água eficiente deve-se considerar o abastecimento de água em quantidade e qualidade. Em quantidade suficiente que consiga atender todas as necessidades de consumo de determinada comunidade e em qualidade adequada para todas as finalidades de consumo.

b) Esgotamento sanitário

O tipo de esgotamento sanitário das residências são: fossa séptica e sumidouro. A fossa séptica é responsável por receber todos os esgotos da residência. De acordo com a Norma Brasileira - NBR no 7229/93, que trata de fossas sépticas, a distância entre a fossa e os limites de terrenos, construções e sumidouros é de no mínimo 1,5 metros $(\mathrm{m})$. Um dos motivos desta condição é evitar danos às construções próximas, ao sumidouro e vizinhos em caso de vazamento

${ }^{2}$ Informação fornecida pela Gerência de Água da SANEAGO de Goiânia-GO, em outubro de 2016. 
(RIBEIRO \& ROOKE, 2010). Entretanto, o que foi observado na realidade é o descumprimento desta norma, as fossas sépticas das residências do Jardim do Cerrado estão praticamente encostadas nos muros, residências e sumidouros (Figura 5).

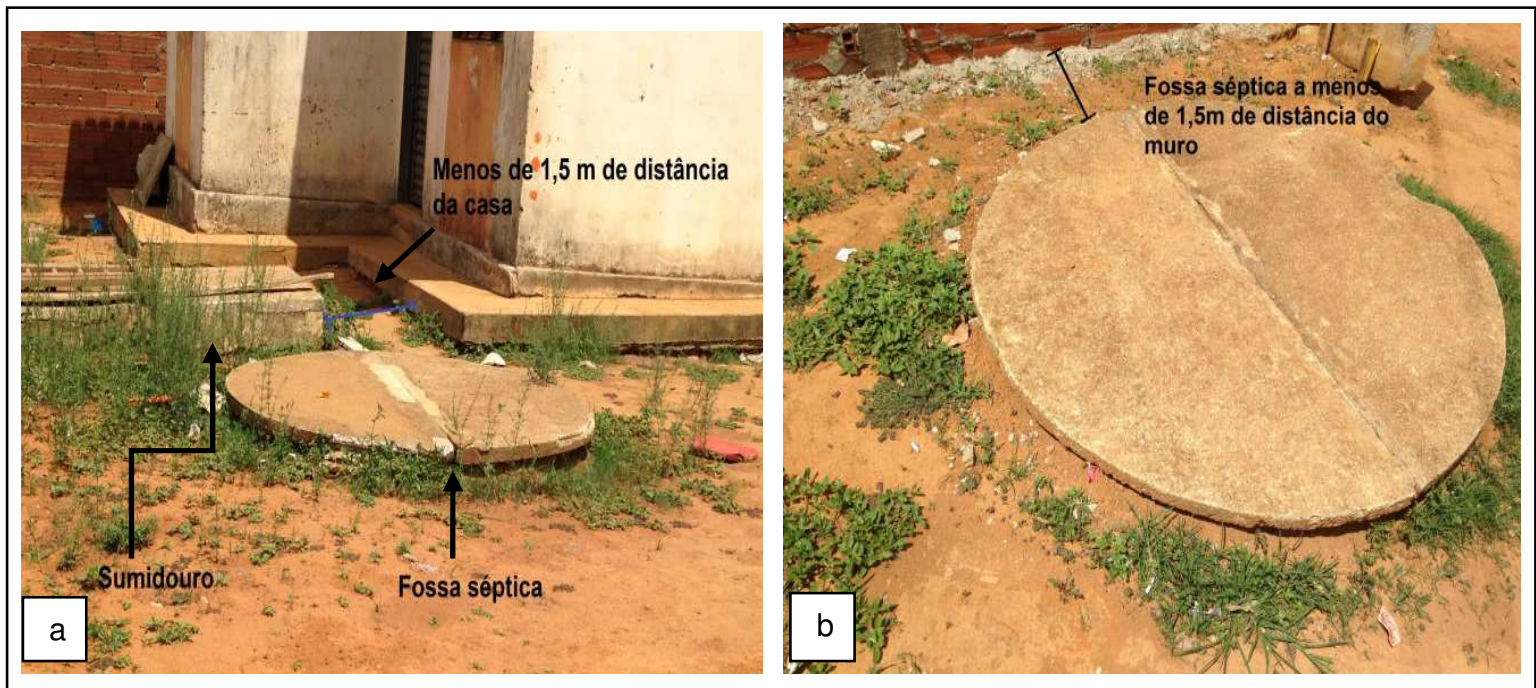

FIGURA 5 - Fossa séptica e sumidouro das residências do Jardim do Cerrado construídas de maneira irregular.

Fonte: Acervo pessoal. Data: 19/11/2016.

$\mathrm{Na}$ imagem (a) observa-se que a fossa séptica está muito próxima do sumidouro e da residência, na outra imagem (b), a fossa está praticamente encostada no muro. Nos dois exemplos, a distância mínima de 1,5m entre a fossa séptica e demais construções - estabelecida pela NBR - foram descumpridas. Foi encontrado no Jardim do Cerrado I esgoto escorrendo a céu aberto nas vias do bairro - o mau cheiro era muito forte (Figura 6). 


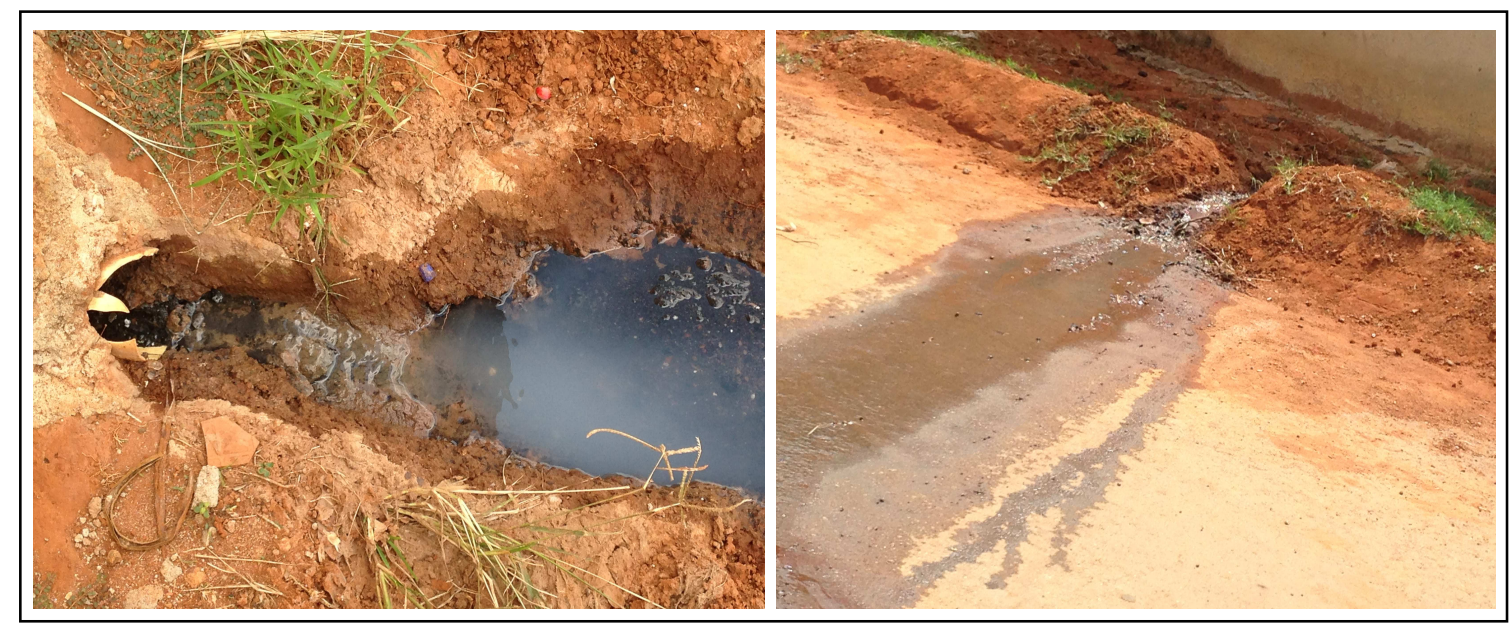

FIGURA 6 - Esgoto doméstico extravasando de uma residência e escorrendo pelas vias do bairro.

Fonte: Acervo pessoal, data: 19/11/2016.

Os moradores demonstraram muita insatisfação com relação ao tipo de esgotamento sanitário do bairro. As respostas são apresentadas na Tabela 2.

TABELA 2 - Respostas dos moradores do Jardim Cerrado sobre questões relacionadas ao esgotamento sanitário.

\begin{tabular}{|c|c|c|}
\hline Questões & Sim & Não \\
\hline Você sabia que existe uma ETE no seu bairro? & 48 & 12 \\
\hline $\begin{array}{c}\text { Você está satisfeito com a forma de esgotamento } \\
\text { sanitário da sua residência (fossa séptica e } \\
\text { sumidouro)? }\end{array}$ & 16 & 44 \\
\hline $\begin{array}{l}\text { Você recebeu alguma orientação sobre o } \\
\text { funcionamento e manutenção da fossa séptica? }\end{array}$ & 2 & 58 \\
\hline
\end{tabular}

Fonte: Elaborado pelos autores (2016)

Todos os moradores participantes da pesquisa relataram no momento de aplicação do questionário que as fossas exalam mau cheiro (o cheiro retorna pelos ralos dos banheiros), que existem muitas baratas que são atraídas pela fossa e que a manutenção da fossa é muito onerosa. Todos reclamaram dos gastos financeiros para limpar a fossa séptica, porque a mesma não suporta a capacidade de efluentes que são lançados. Nas residências em que moram até quatro pessoas, eles fazem a limpeza da fossa a cada seis meses, acima desta quantidade, os moradores relataram que a limpeza deve ser feita a cada quatro meses. Ressaltando que as empresas prestadoras deste tipo de serviço cobram entre $R \$ 200,00$ e $R \$ 250,00$ para limpar uma fossa.

Diante dos problemas e prejuízos causados pela fossa séptica, os moradores questionaram o porquê de não possuírem rede geral de esgoto sendo que existe uma Estação de Tratamento de Esgoto no bairro. Eles também demonstraram 
grande descontentamento em ter que suportar o mau cheiro proveniente da ETE todas as tardes e ainda o mau cheiro das fossas sépticas.

Sabe-se que no Brasil, o déficit dos serviços de abastecimento de água e esgotamento sanitário é mais acentuado nas populações de baixa renda, que os maiores problemas de saúde pública encontram nesta faixa populacional de baixa renda (SILVA \& MACHADO, 2001). Estas carências de saneamento evidenciam características de desigualdades sob os aspectos regionais, renda familiar e localização do domicílio (HELLER \& NASCIMENTO, 2005). É notório que as desigualdades existentes no Brasil não se expressam apenas do ponto de vista econômico, mas também sobre o viés do saneamento básico. $O$ Jardim do Cerrado exemplifica muito bem esta afirmativa.

c) Resíduos sólidos

Um dos maiores problemas enfrentados na sociedade pós-moderna se refere ao grande consumo de produtos e serviços que consequentemente gera excesso de resíduos sólidos que são, muitas vezes, descartados em locais inadequados no ambiente. Com o volume crescente de resíduos, agravam-se os problemas relacionados com a aglomeração populacional em áreas urbanas e, consequentemente diminui ou encarecem as áreas destinadas à construção de aterros sanitários (MARTINS et al., 2016).

Os resíduos sólidos constituem problemas sanitário, econômico e principalmente de ordem estética. De acordo com informações de moradores locais, o caminhão coletor de lixo passa no bairro três vezes por semana ( $3^{a}$, $5^{\underline{a}}$ e sábado). Quando questionada sobre o caminhão da coleta seletiva, uma moradora relatou que no início, assim que o bairro foi inaugurado, o caminhão passava regularmente, mas que após um tempo parou de passar. Na Figura 7 são apresentadas as respostas dos moradores sobre o conhecimento do programa Coleta Seletiva em Goiânia e sobre a forma como separam os resíduos domiciliares.
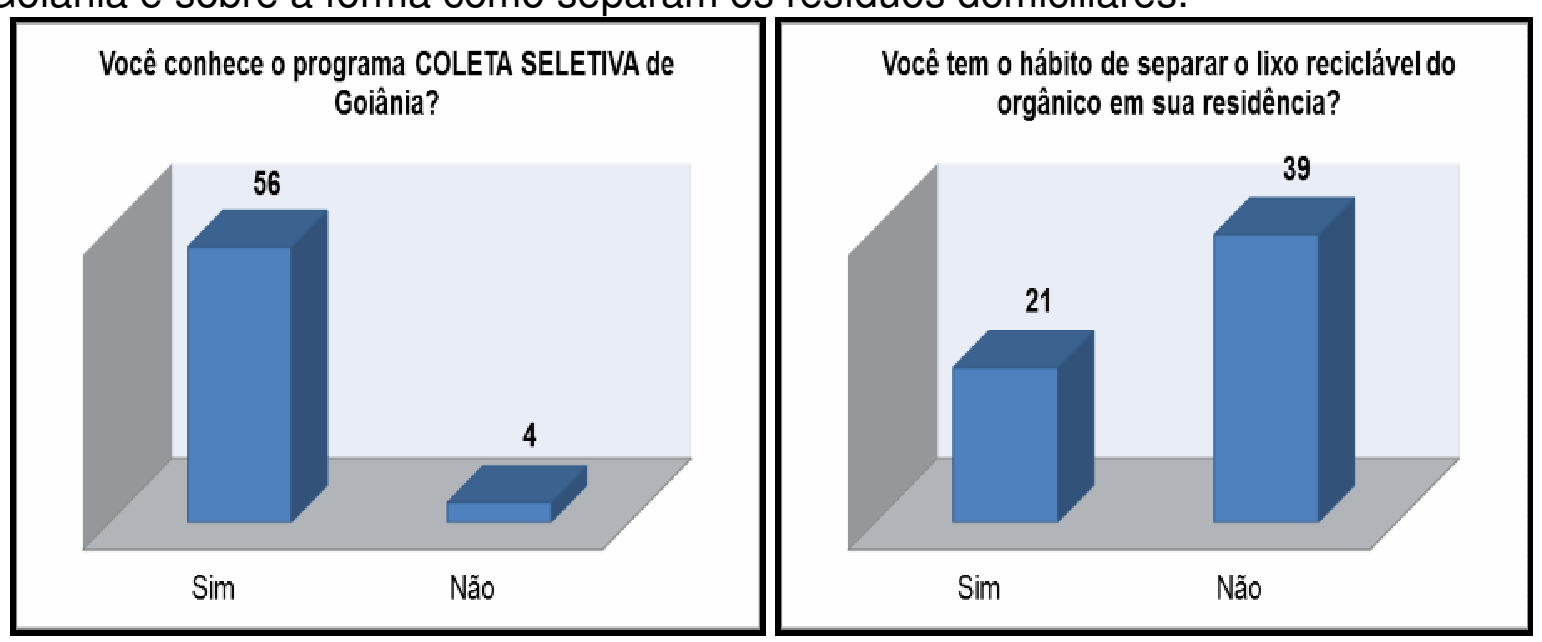

FIGURA 7 - Respostas dos moradores do Jardim Cerrado sobre questões relacionadas aos resíduos sólidos domiciliares.

Fonte: Elaborado pelos autores (2016)

Apesar de $93 \%$ dos participantes da pesquisa conhecerem o programa coleta seletiva, o percentual dos que não têm o hábito de separar o lixo reciclável do não reciclável ainda é alto (65\%). Ao percorrer as ruas do Jardim do Cerrado I a IV o que 
mais se observa nas esquinas e lotes vagos são resíduos sólidos, tanto domésticos quanto de construção civil e restos de poda (Figura 8).

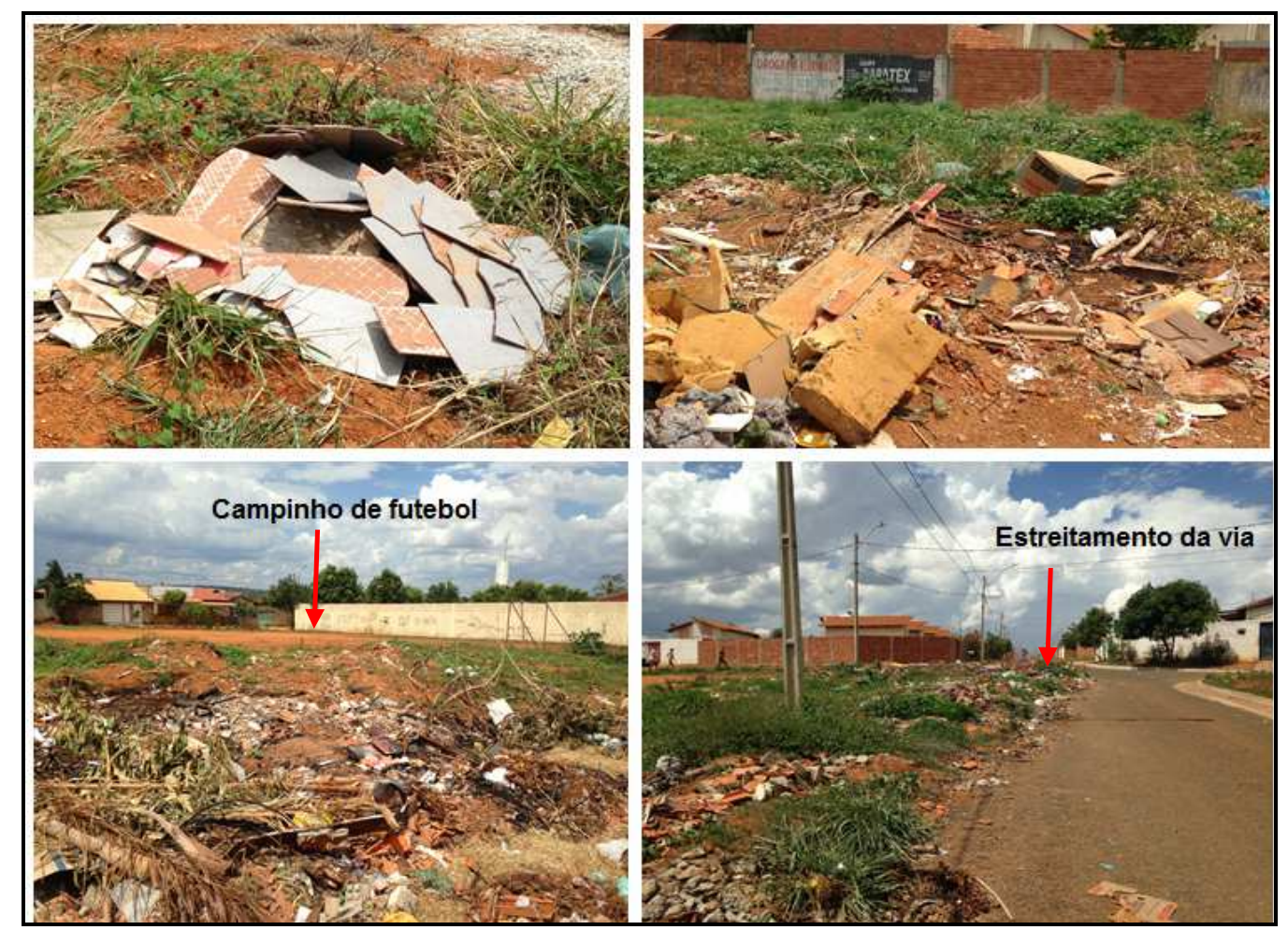

FIGURA 8 - Resíduos sólidos em diversos locais do Residencial Jardim do Cerrado. Fonte: Acervo pessoal. Data: 20/11/2016.

Em alguns locais a quantidade de lixo é tão grande que chega a invadir as ruas e atrapalhar a passagem de veículos. O campinho de futebol, por exemplo, que deveria ser um local de lazer das crianças e adolescentes, se transformou em um depósito de lixo. Ao percorrer o bairro percebeu-se que é comum as pessoas descartarem resíduos, principalmente os de construção civil, móveis, restos de poda de árvore e também resíduos recicláveis. A Resolução CONAMA № 307 de 2002 estabelece o seguinte sobre os resíduos de construção civil:

"Art. 4ํำ Os resíduos da construção civil não poderão ser dispostos em aterros de resíduos domiciliares, em áreas de "bota fora", em encostas, corpos d’água, lotes vagos e em áreas protegidas por Lei, obedecidos os prazos definidos no art. 13 desta Resolução (...) Art. 11. Fica estabelecido o prazo máximo de doze meses para que os municípios e o Distrito Federal elaborem seus Planos Integrados de Gerenciamento de Resíduos de Construção Civil, contemplando os Programas Municipais de Gerenciamento de Resíduos de Construção Civil oriundos de geradores de pequenos volumes, e o prazo máximo de dezoito meses para sua implementação (...) Art. 13. No prazo máximo de dezoito meses os Municípios e o Distrito Federal deverão cessar a disposição de resíduos de construção civil em aterros de resíduos domiciliares e em áreas de "bota fora". (BRASIL, 2002, artigo 4ํㅜㄴ 11 e 13). 
A COMURG, empresa responsável pela limpeza urbana de Goiânia, justifica o recebimento dos RCC no aterro sanitário municipal, por meio da Resolução COMURG no 20 de 07 de junho de 2016:

Considerando que Goiânia ainda não possui o Plano Integrado de Gerenciamento de Resíduos de Construção Civil e que o aterro sanitário utiliza o RCC como sub-base dos pátios de manobra, a reforma de estradas internas e como parte da camada de cobertura dos resíduos domiciliares, considerou que é viável o recebimento do RCC classe A e C (GOIÂNIA, 2016).

A COMURG que também é a administradora do aterro sanitário de Goiânia estabelece na mesma resolução que os resíduos de construção civil não são coletados pela COMURG, e que devem ser levados para "o aterro pelo próprio gerador ou por empresas particulares por ele contratada, em caçambas ou caminhões" (GOIÂNIA, 2016). No entanto, o gerador só poderá realizar este descarte mediante pagamento de guia; o descarte é gratuito para pequenos geradores (até $500 \mathrm{~kg}$ ). A Figura 9 apresenta a opinião dos moradores com relação às dificuldades em destinar adequadamente os resíduos de construção civil.

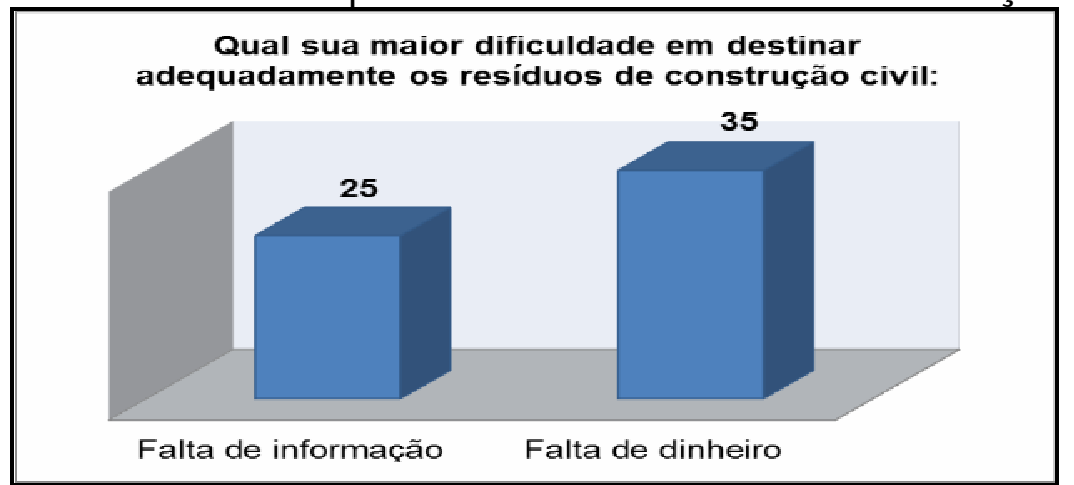

FIGURA 9 - Opinião dos moradores sobre as dificuldades em destinar os RCC.

Fonte: Elaborado pelos autores (2016).

$\mathrm{Na}$ opinião de $42 \%$ dos moradores participantes a maior dificuldade em destinar adequadamente os RCC é a falta de informação, ou seja, não sabem o que fazer com resíduo ou para onde devem levar. A falta de recursos financeiros é o maior impedimento na opinião de $58 \%$, eles sabem que devem contratar uma caçamba, mas não possuem recursos suficientes para isso.

d) Drenagem de águas pluviais

A falta de sistema de drenagem pluvial é um dos principais problemas causados pela urbanização. Com a retenção de água na superfície do solo, surgem inúmeras consequências que interferem diretamente na qualidade de vida da população (CAVENAGHI \& LIMA, 2015).

Além dos alagamentos e inundações, a falta de drenagem urbana propicia o aparecimento de doenças como a leptospirose, diarreias, febre tifoide e a proliferação dos mosquitos anofelinos, que podem disseminar a malária, entre outras doenças (BRASIL, 2007).

A drenagem das águas pluviais no bairro é outro problema de saneamento básico. O Jardim do Cerrado que foi um bairro "planejado", não possui uma infraestrutura urbana de saneamento compatível com a de um bairro planejado. As 
ruas do bairro não possuem meio fio e nem bocas de lobo, as águas da chuva escorrem em alta velocidade, danificando o asfalto e formando erosões nas vias que ficam em áreas mais inclinadas e não asfaltadas (Figura 10 e 11).

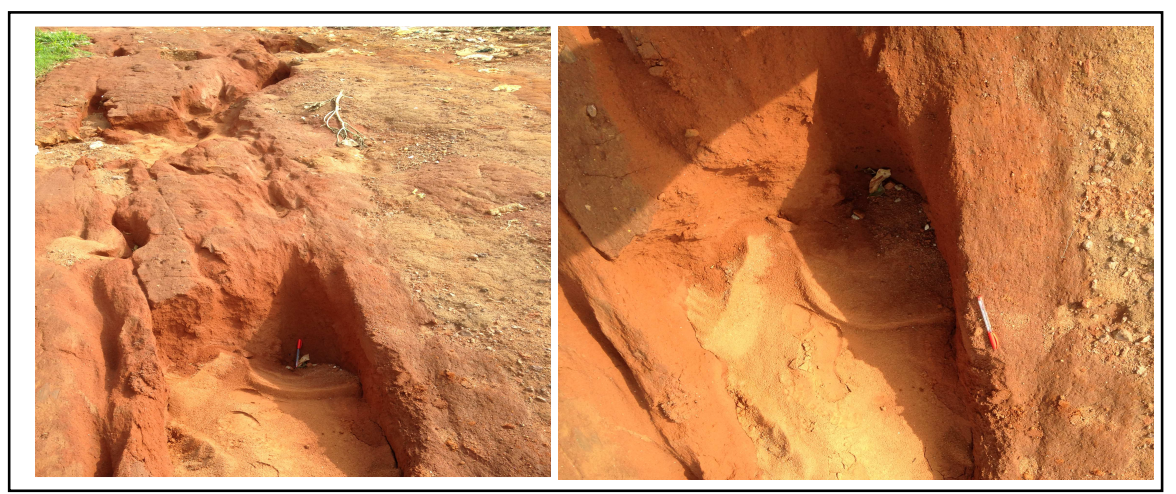

FIGURA 10 - Erosões provocadas pelas águas pluviais na Avenida Rainha dos Lagos no Jardim Cerrado III.

Fonte: Acervo pessoal. Data: 17/12/2017.

Foi observada a inexistência de rede de drenagem pluvial em vários locais no bairro. Com exceção de algumas ruas, o bairro não possui meio fio e bocas de lobo. Em outros locais o asfalto já se encontra danificado pela força das águas pluviais (Figura 11).

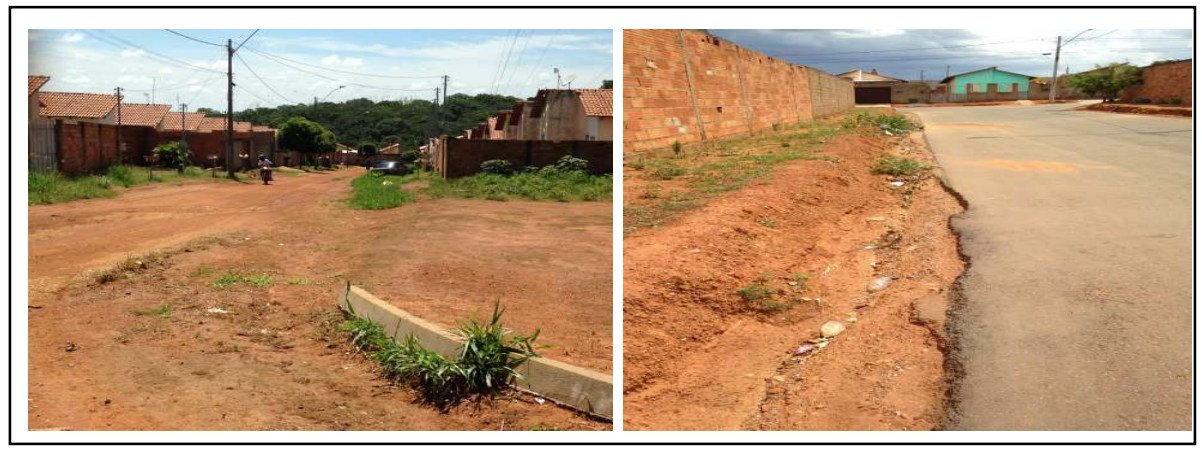

FIGURA 11 - Inexistência de infraestrutura de drenagem de águas pluviais no Residencial Jardim do Cerrado I a IV.

Fonte: Acervo pessoal. Data: 20/11/2016.

A falta de drenagem pluvial também prejudica a locomoção dos moradores no bairro devido aos pontos de alagamento e enxurradas que formam durante o período chuvoso (Figura 12). 

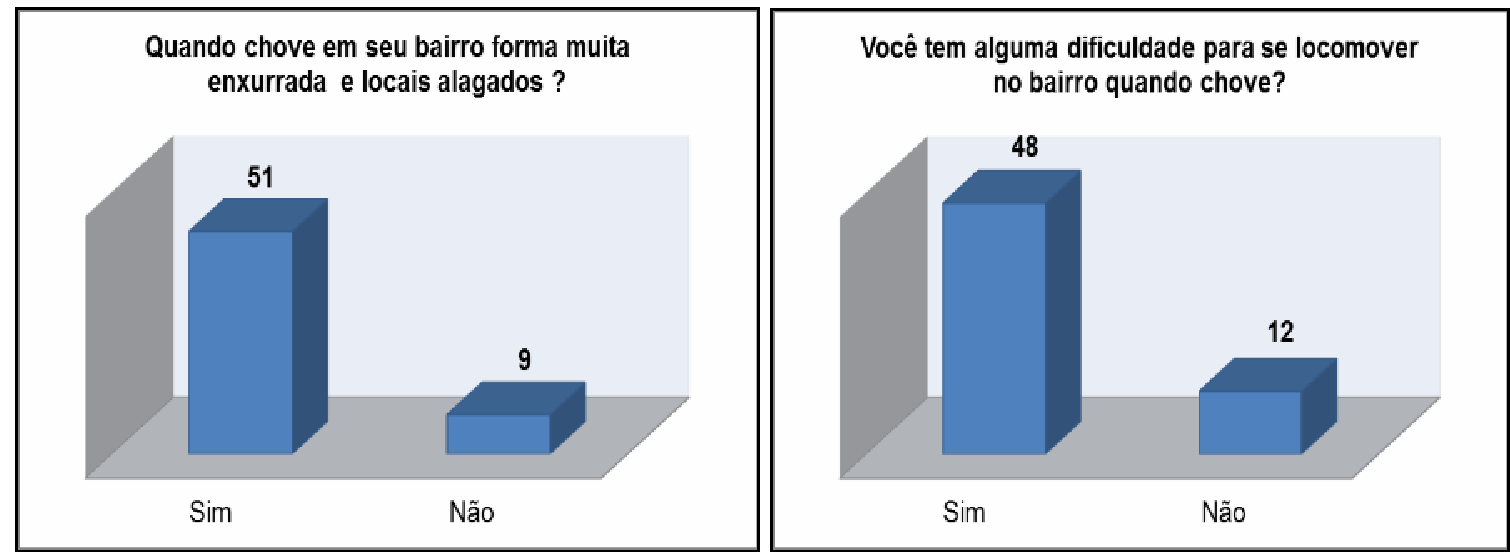

FIGURA 12 - Respostas dos moradores do Jardim Cerrado sobre drenagem pluvial, Goiânia - GO.

Fonte: Elaborado pelos autores (2016)

Moradores do Jardim Cerrado III relataram que até o mês de novembro de 2016 não existiam bocas de lobo em nenhuma rua do bairro. Mas que na primeira semana de dezembro de 2016 eles foram surpreendidos com a construção rápida de algumas bocas de lobo em poucas ruas do setor. Ao observar o fundo destas bocas de lobo, percebe-se que estas são apenas uma cava cimentada no interior com tampas pré-moldadas e que não estão conectadas a nenhuma tubulação de rede de drenagem pluvial (Figura 13). A inexistência de drenagem de águas pluviais pode danificar as vias públicas, iniciar processos erosivos, provocar alagamentos e enchentes que consequentemente impacta negativamente a saúde pública.

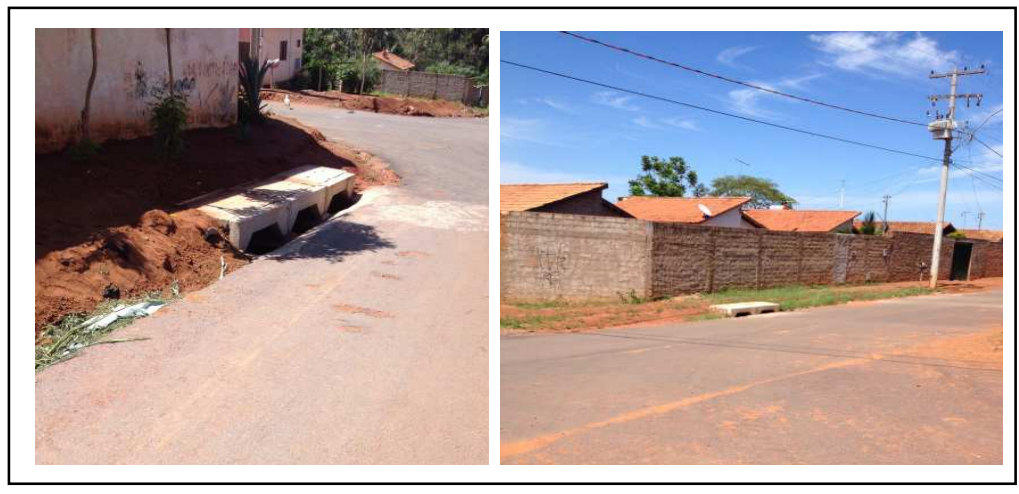

FIGURA 13 - Bocas de lobo para "inglês ver" construídas no mês de dezembro de 2016 no Jardim Cerrado III.

Fonte: Acervo pessoal. Data: 17/12/2016.

A inexistência de drenagem de águas pluviais pode danificar as vias públicas, iniciar processos erosivos, provocar alagamentos e enchentes que consequentemente impacta negativamente a saúde pública. TUCCI (2002) destaca alguns impactos sobre a população, a saber: "prejuízos de perdas materiais e humanas; interrupção da atividade econômica das áreas inundadas; contaminação por doenças de veiculação hídrica como leptospirose, cólera, entre outros" (TUCCl, 2002, p. 11). 


\section{CONCLUSÃO}

A partir do estudo de caso no Residencial Jardim Cerrado observa-se que a maioria das vias não foi asfaltada, não possui rede de drenagem pluvial o que tem favorecido o desenvolvimento de processos erosivos já severos em alguns pontos. As fossas sépticas que foram construídas pela incorporadora não seguiram as regras básicas da $A B N T$, prejudicando a vida útil e funcionamento da fossa. $A$ população deste bairro encontra-se segregada do centro urbano, não possui acesso a praças, centros esportivos ou outras opções de lazer.

É importante ressaltar também que o manejo de resíduos sólidos no bairro merece ser tratado com mais atenção pela prefeitura municipal, principalmente, no que se refere à regularidade do caminhão coletor de resíduos domésticos comuns e recicláveis. É exorbitante a quantidade de resíduos descartados em lotes vagos no bairro. Sugere-se que seja realizado um trabalho de educação ambiental com a população do bairro para incentivá-las a fazer a separação dos resíduos recicláveis em seus domicílios e conscientiza-las sobre a destinação adequada dos resíduos sólidos domésticos, de construção civil, eletroeletrônicos, móveis velhos, entre outros e informa-las sobre os riscos que o acúmulo indevido destes resíduos pode causar à saúde pública.

\section{AGRADECIMENTOS}

A CAPES e à FAPEG pelo auxílio financeiro. Projeto de pesquisa: As Interferências do Programa Minha Casa Minha Vida na Região Metropolitana de Goiânia (6.4.0.00-0 Chamada NEPEC/ PROPE/ PUC Goiás, № 4550).

\section{REFERÊNCIAS \\ BRASIL. RESOLUÇÃo CONAMA N. $307 /$ 2002. Disponível em: http://www.mma.gov.br/port/conama/legiabre.cfm?codlegi=307. Acesso em: $01 \mathrm{fev}$. 2017.}

Plano Diretor participativo: guia para elaboração pelos municípios e cidadãos. Brasília: Ministério das Cidades; Confea, 2007.

CARDOSO, A.; ARAGÃO, T. A. Do Fim do BNH ao Programa Minha Casa Minha Vida: 25 anos da política habitacional no Brasil. In CARDOSO, A. (Org.). 0 Programa Minha Casa Minha Vida e Seus Efeitos Territoriais. Rio de Janeiro: Letra Capital, 2013.

CAVENAGHI, P. T. LIMA, M. Plano Diretor: como a geotecnologia tem facilitado a gestão dos municípios. 2009 Site: www.img.com.br. Acesso: 15 Nov. 2015.

GALVÃO JÚNIOR, A.C.; SOBRINHO, G.B.; SILVA, A.C. Painel de Indicadores para Planos de Saneamento Básico. In: PHILIPPI JÚNIOR, A. \& GALVÃO JÚNIOR, A.C. (Ed.). Gestão do Saneamento Básico: abastecimento de água e esgotamento sanitário. Barueri: Manole. p. 1040-1068, 2012.

GOIÂNIA. Prefeitura de Goiânia - COMURG 2016 Disponível em: http://www.goiania.go.gov.br/shtml/coletaseletiva/principal.shtml. Acesso em: 13 Ago. 2016. 
HELLER, L.; NASCIMENTO, N.O. Pesquisa e desenvolvimento na área de saneamento no Brasil: necessidades e tendências. Engenharia Sanitária e Ambiental, v.10 n.1 p.24-35, 2005.

IBGE - Instituto Brasileiro de Geografia e Estatística. (2015) Primeiros resultados definitivos do Censo 2010. Disponível em: <http://www.ibge.gov.br/home/presidencia/noticias/noticia_visualiza.php?id_noticia=1 866\&id_pagina=1>. Acesso em: 29 nov.2016.

LUCAS, E. R. Cidade na Cidade: Habitação social e Produção do Espaço Urbano em Goiânia. em Goiânia/Goiás, 2016. 172 f. (Dissertação de mestrado) programa de pós-graduação em Arquitetura - Projeto e Cidade da Faculdade de Artes Visuais (FAV) da Universidade Federal de Goiás, 2016.

MARTINS, L. O. S.; SILVA, L. T; CARNEIRO, R. A. F; VELAME, J. L. Análise da viabilidade econômica e financeira da implantação de usina de geração de energia a partir de resíduos sólidos urbanos no município de Santo Antônio de Jesus - BA, Revista Unigranrio, ANO III, v., n.2, 2016.

MEDEIROS FILHO, F. C. Livro de Abastecimento de Água, Universidade Federal de Campina Grande - UFCG, Campina Grande - PB, 2008.

MORAIS, J. M. da S. C.; LABAKI, L. C. CFD como ferramenta para simular ventilação natural interna por ação dos ventos: estudos de caso em tipologias verticais do "Programa Minha Casa, Minha Vida". Ambiente Construído, Porto Alegre, v. 17, n. 1, p. 223-244, jan./mar. 2017. http://dx.doi.org/10.1590/s167886212017000100133.

MÜLLER, S. C.; LIMA, J. J. F. O espaço para crianças produzido pelo programa Minha Casa, Minha Vida: estudo de caso na região metropolitana de Belém, PR. Ambiente Construído, Porto Alegre, v. 17, n. 2, p. 97-117, abr./jun. 2017. Construído. http://dx.doi.org/10.1590/s1678-86212017000200148.

RIBEIRO, P. J.; ROOKE, A. T. Programa educativo em esquistossomose: modelo de abordagem metodológica. Revista de Saúde Pública, v. 38, n. 3, p. 415-421, 2010.

ROLNIK, R.; PEREIRA, A. L. S.; MOREIRA, F. A.; ROYER, L. O.; IACOVINI, R. F. G.; NISIDA, V. C. O Programa Minha Casa Minha Vida nas regiões metropolitanas de São Paulo e Campinas: aspectos socioespaciais e segregação. Caderno Metrópoles, n. 33, p. 127-154, São Paulo, 2005.

SILVA, R. T.; MACHADO, L. Serviços urbanos em rede e controle público do subsolo — novos desafios à gestão urbana. São Paulo Rev. Perspec. 2001; 15(1): 102-11.

TUCCI, C. E. M. Gerenciamento da Drenagem Urbana, Revista Brasileira de Recursos Hídricos, v.2 n.2 p 5- 312002.

XAVIER, A. R; LORETO, A. S. Comparação entre os Custos Cálculados do Plano Municipal de Saneamento Básico do Município de Divino das Laranjeiras, Minas 
Gerais e a Estimativa de Investimentos Utilizando o Índice Multidimensional de Saneamento Básico. I Jornada de Iniciação Científica da FACIG - 17 e 18 de Novembro de 2016. 